\title{
Impairment of Di(2-Ethylhexyl) Phthalate on Cellular Immunity in Kunming Mice
}

\author{
Yufen Tian1, Deli Xu' ${ }^{2 *}$, Shengqun Zhang2, Jinyan Zhang2, Zhicun Sun², Xiangfang Liu², \\ Xin Wang', Xia Wang', Daqian Meng2 \\ ${ }^{1}$ Library, Qufu Normal University, Qufu, China \\ ${ }^{2}$ College of Life Sciences, Qufu Normal University, Qufu, China \\ Email: xudl1975@163.com
}

Received 5 May 2015; accepted 3 July 2015; published 6 July 2015

Copyright (C) 2015 by authors and Scientific Research Publishing Inc.

This work is licensed under the Creative Commons Attribution International License (CC BY). http://creativecommons.org/licenses/by/4.0/

(c) () Open Access

\begin{abstract}
Immunity is crucial to the health of animals and it can determine their survival and fitness. Di(2ethylhexyl) phthalate (DEHP) is widely used as a plasticizer and hence is the most abundant phthalate in the environment. Exposure to DEHP is of great concern for human health. In the present study, we tested the hypothesis that exposure to DEHP would suppress T cell-mediated immunity in mice. Twenty adult male Kunming mice were randomly assigned into the control $(n=10)$ and the DEHP treatment $(n=10)$ groups. Both groups have free access to food and water, while the mice in the latter group drank DEHP solution $(2000 \mathrm{mg} / \mathrm{L})$ for 42 days. T cell-mediated immunity assessed by phytohaemagglutinin (PHA) response was depressed in the DEHP treated mice compared with the controls, however, wet thymus and spleen mass, white blood cells were not influenced by DEHP treatment. Taken together, different immunological parameters responded differently to DEHP treatment in Kunming mice.
\end{abstract}

\section{Keywords}

Di(2-Ethylhexyl) Phthalate (DEHP), Kunming Mice, Phytohaemagglutinin Response

\section{Introduction}

The immune system protects animals against environmental pathogens, which is crucial for their health and is important to determine their survival and fitness [1] [2]. However, immune function is influenced by many factors including endocrine disruptors such as di(2-ethylhexyl) phthalate (DEHP) [3]-[6].

DEHP, produced at annual quantities of 2 million tons and widely used in medical devices and plastics, is one

\footnotetext{
*Corresponding author.
}

How to cite this paper: Tian, Y.F., Xu, D.L., Zhang, S.Q., Zhang, J.Y., Sun, Z.C., Liu, X.F., Wang, X., Wang, X. and Meng, D.Q. (2015) Impairment of Di(2-Ethylhexyl) Phthalate on Cellular Immunity in Kunming Mice. Open Journal of Animal Sciences, 5, 270-276. http://dx.doi.org/10.4236/ojas.2015.53031 
of the principal phthalates causing human health concerns [7]-[9]. DEHP has endocrine-disrupting property [10]-[12]. Many researchers have focused on the reproductive toxicology of DEHP in rodents $(25 ; 26)$ and human [13] [14]. The ability of DEHP to impact on immune and allergic responses has been examined [5] [6] [15]. Moreover, some investigators have found that DEHP treatment could inhibit B cell proliferation and reduces the abundance of IgM-secreting cells in cultured immune tissues [16]. However, whether DEHP treatment could suppress cellular immunity still remains unclear.

Phytohaemagglutinin (PHA) response can be used to evaluate mammalian cellular immunity, which is one arm of adaptive immune system and generally responsible for intracellular pathogen control [17] [18]. Immune organs including thymus and spleen are also indicative of immune function [19]-[21]. Thymus is essential for primary T cell development [19], and a larger spleen is representative of stronger immunity [21]. Total white blood cells (or leukocytes, WBC), which are crucial for immune responses against pathogens, are useful to assess the overall health [20].

In the present study, we tested the hypothesis that DEHP would have great influences on immune function in Kunming mice. We expected that immunological parameters including cellular immunity, thymus and spleen mass and white blood cells would be suppressed in DEHP treated mice compared with the controls.

\section{Materials and Methods}

\subsection{Animals and Experimental Design}

All animal procedures were licensed under the Institutional Animal Care and Use Committee of Qufu Normal University. Adult male Kunming mice (age: 6 months) used in this study were obtained from the Experiment Animal Center in Jining Medical College of Shangdong province. The experiment was carried out from September 6 to October 25 in 2012. The animals were housed individually in plastic cages $(30 \mathrm{~cm} \times 15 \mathrm{~cm} \times 20 \mathrm{~cm}$ ) with sawdust as bedding. The raising conditions are semi-natural in which maximum and minimum ambient temperature and humidity were described in Figure A and Figure B, and the photoperiod was natural light. Standard rat pellets chow (Animal Breeding Center in Jining Medical College, Jining, China) and water were provided ad libitum. After body mass stabilized, 20 mice were randomly divided into the control group $(\mathrm{n}=10)$

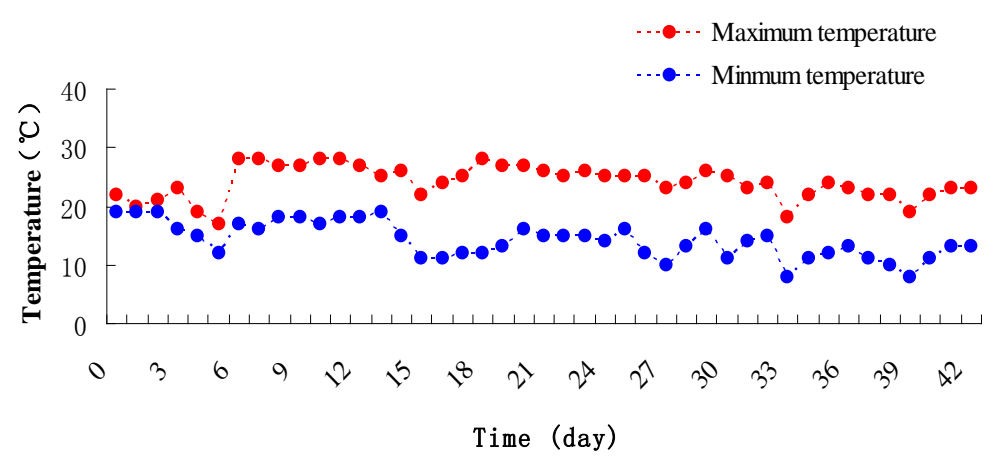

Figure A. The changes of maximum and minimum temperature during the course of the experiment.

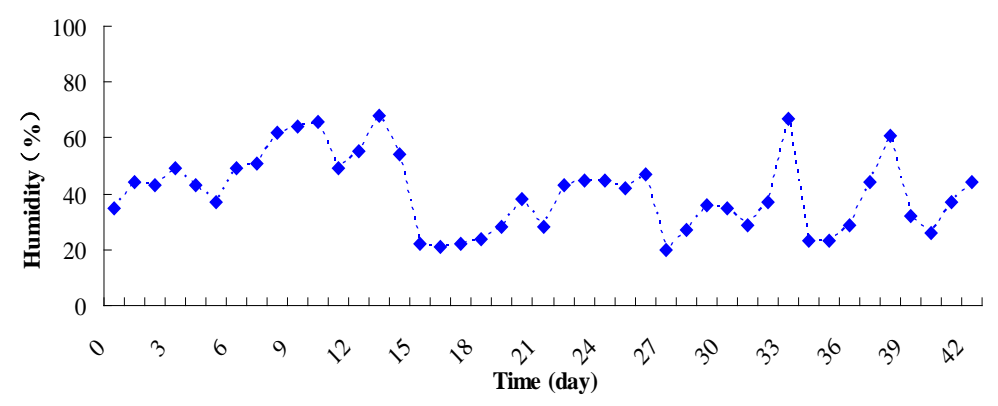

Figure B. The changes of humidity during the course of the experiment. 
and the DEHP treated group $(\mathrm{n}=10)$ in which each mouse drank DEHP solution $(2000 \mathrm{mg} / \mathrm{L})$. The period of the experiment was 42 days. Day 0 and day n represented initial day and $\mathrm{n}$ days of treatment, respectively. 4 mice in the DEHP group died on day 7, 20, 34, 40 respectively, and 2 mice in the control group died on day 15, 35 respectively. The data of the six mice were not included in the subsequent statistical analysis.

\subsection{Cellular Immunity Assays}

PHA response was measured as described previously [18] [22]. Specifically, mice in the control and DEHP groups on day 39 were caught, then we measured their footpad thickness of the left hind foot with a micrometer (Digimatic Indicator ID-C Mitutoyo Absolute cod. 547-301, Japan) to $\pm 0.01 \mathrm{~mm}$. Immediately thereafter, mice in both groups were injected subcutaneously $0.1 \mathrm{mg}$ of PHA (PHA-P, Sigma L-8754) dissolved in $0.03 \mathrm{~mL}$ of sterile saline (pH 7.4) in the middle of the footpad. After $6 \mathrm{~h}, 24 \mathrm{~h}, 48 \mathrm{~h}$ and $72 \mathrm{~h}$ injection, we measured footpad thickness. The PHA response (i.e., cellular immunity) was calculated as the difference between pre- and postinjection measurements divided by initial footpad thickness $($ PHA response $=($ post PHA - pre PHA) $/$ pre PHA). Six measures of footpad thickness were taken to obtain the value of each mouse [22].

\subsection{Organs}

Organs were measured as described previously [22]. In brief, the visceral organs, including heart, thymus, lungs, liver, spleen, kidneys, adrenal glands, testes, epididymis, seminal vesicals and the digestive organs with contents (i.e., stomach, small intestine, caecum and colon) were dissected and weighed ( $\pm 1 \mathrm{mg}$ ). The stomach, small intestine, caecum and colon were rinsed with saline to eliminate all the gut contents, before being weighed.

\subsection{White Blood Cells Assays}

At the end of the experiment, after collecting trunk blood, $20 \mu \mathrm{L}$ whole blood was diluted immediately in 0.38 $\mathrm{mL}$ solution containing $1.5 \%$ glacial acetic acid, $1 \%$ crystal violet (Sigma) and the leukocytes were counted in an improved Neubauer chamber using microscope. The total number of WBC was determined by counting all leucocytes in the four corner large-squares of the Neubauer chamber, and multiplying the raw data by $5 \times 10^{7}$ to obtain the final values $\left(10^{9}\right.$ cells/L) [23].

\subsection{Statistical Analysis}

Data were analyzed using SPSS 13.0 software (SPSS Inc., Chicago, IL, USA). Prior to all statistical analyses, data were examined for normality and homogeneity of variance, using Kolmogorov-Smirnov and Levene tests, respectively. The ratio values such as PHA response were subjected to arcsine transformation. The differences of body mass between the control and DEHP treated groups were analyzed by independent-samples t-test. Group differences in wet organ mass with body mass as the covariate were analyzed by General Linear Model multivariate analysis followed by Bonferroni post hoc tests. Group differences in other parameters (PHA response, WBC) were analyzed by independent-samples t-test. Results were expressed as mean $\pm \mathrm{SE}$, and $P<0.05$ was considered to be statistically significant.

\section{Results}

\subsection{Body Mass}

On day 0 , body mass between the control and DEHP groups was not different $(\mathrm{t}=-0.666, \mathrm{df}=12, P=0.518)$. There was no difference of body mass between these two groups from day $1(\mathrm{t}=-0.437, \mathrm{df}=12, P=0.670)$ to day $42(\mathrm{t}=-0.064, \mathrm{df}=12, P=0.950)$ (Figure 1$)$.

\subsection{Organs}

DEHP treatment decreased the masses of stomach with contents and seminal vesical while increased the mass of colon (Table 1). The masses of thymus, spleen and other organs were all not influenced by DEHP treatment (Table 1). 


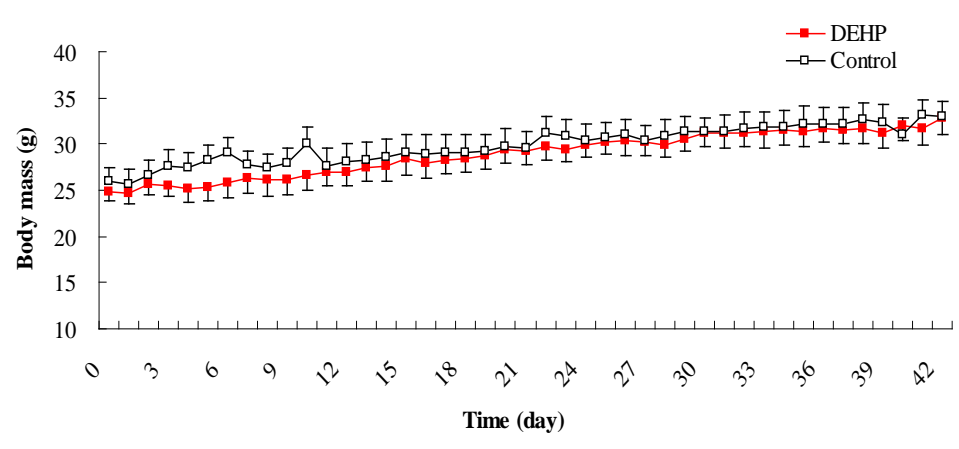

Figure 1. Changes of body mass in mice during DEHP treatment. Values are means \pm SE. Body mass on day 0 between the control and DEHP treatment groups did not differ significantly.

Table 1. Effect of DEHP treatment on wet organ mass in Kunming mice.

\begin{tabular}{|c|c|c|c|c|}
\hline \multirow{2}{*}{$\begin{array}{l}\text { Parameters } \\
\text { Sample size }\end{array}$} & \multirow{2}{*}{$\begin{array}{c}\text { Control group } \\
8\end{array}$} & \multirow{2}{*}{$\begin{array}{c}\text { DEHP group } \\
6\end{array}$} & \multicolumn{2}{|c|}{ Statistical summary } \\
\hline & & & $\mathrm{F}_{1,10}$ & $P$ \\
\hline Heart (mg) & $153 \pm 6$ & $163 \pm 8$ & 0.826 & 0.385 \\
\hline Lungs (mg) & $334 \pm 63$ & $378 \pm 80$ & 0.185 & 0.676 \\
\hline Thymus (mg) & $43 \pm 10$ & $62 \pm 12$ & 1.678 & 0.224 \\
\hline Liver (mg) & $1912 \pm 91$ & $1829 \pm 115$ & 0.322 & 0.583 \\
\hline Spleen (mg) & $160 \pm 14$ & $125 \pm 18$ & 2.461 & 0.148 \\
\hline Kidneys (mg) & $502 \pm 20$ & $493 \pm 25$ & 0.090 & 0.771 \\
\hline Adrenal glands (mg) & $9 \pm 2$ & $17 \pm 3$ & 4.563 & 0.058 \\
\hline Stomach with contents (mg) & $845 \pm 63^{\mathrm{a}}$ & $580 \pm 79^{\mathrm{b}}$ & 6.838 & 0.026 \\
\hline Stomach (mg) & $206 \pm 14$ & $233 \pm 17$ & 1.403 & 0.264 \\
\hline Small intestine with contents (mg) & $2608 \pm 261$ & $2419 \pm 330$ & 0.202 & 0.662 \\
\hline Small intestine (mg) & $1170 \pm 109$ & $1295 \pm 138$ & 0.504 & 0.494 \\
\hline Small intestine length (cm) & $69.3 \pm 1.4$ & $64.8 \pm 1.8$ & 3.927 & 0.076 \\
\hline Caecum with contents (mg) & $747 \pm 73$ & $754 \pm 92$ & 0.004 & 0.953 \\
\hline Caecum (mg) & $198 \pm 24$ & $199 \pm 30$ & 0.000 & 0.989 \\
\hline Caecum length (cm) & $3.5 \pm 0.2$ & $3.7 \pm 0.2$ & 0.316 & 0.586 \\
\hline Colon with contents (mg) & $593 \pm 43$ & $585 \pm 54$ & 0.012 & 0.914 \\
\hline Colon (mg) & $271 \pm 11^{\mathrm{a}}$ & $316 \pm 14^{\mathrm{b}}$ & 6.347 & 0.030 \\
\hline Colon length $(\mathrm{cm})$ & $8.8 \pm 0.5$ & $9.2 \pm 0.6$ & 0.184 & 0.677 \\
\hline Total digestive tract (mg) & $1846 \pm 144$ & $2043 \pm 183$ & 0.717 & 0.417 \\
\hline Total digestive tract length $(\mathrm{cm})$ & $82 \pm 2$ & $78 \pm 2$ & 1.790 & 0.211 \\
\hline Epididymis (mg) & $50 \pm 5$ & $40 \pm 6$ & 1.884 & 0.200 \\
\hline Testes (mg) & $266 \pm 13$ & $248 \pm 16$ & 0.808 & 0.390 \\
\hline Seminal vesical (mg) & $173 \pm 12^{\mathrm{a}}$ & $128 \pm 15^{\mathrm{b}}$ & 5.602 & 0.039 \\
\hline
\end{tabular}

Values are means \pm SE.Values for a specific parameter that share different superscripts are significantly different at $P<0.05$, determined by General Linear Model multivariate analysis followed by Bonferroni post hoc tests with body mass as the covariate.

\subsection{White Blood Cells}

WBC did not differ between the control and DEHP treated mice $(\mathrm{t}=0.342, \mathrm{df}=12, \mathrm{P}=0.738$ ) (Figure 2). 


\subsection{Cellular Immune Response}

Compared with the control mice, PHA response in the DEHP treated mice was suppressed significantly after 24 $\mathrm{h}(\mathrm{t}=-2.822, \mathrm{df}=12, P=0.015), 48 \mathrm{~h}(\mathrm{t}=-2.859, \mathrm{df}=12, P=0.014)$ and $72 \mathrm{~h}(\mathrm{t}=-4.126, \mathrm{df}=12, P=0.001)$ of PHA injection (Figure 3). Impact of DEHP treatment on PHA response after $6 \mathrm{~h}$ of postimmunization in DEHP treated mice was near to the significant level in contrast with the control mice $(\mathrm{t}=-2.152, \mathrm{df}=12, P=$ 0.052) (Figure 3).

\section{Discussion}

As expected, cellular immunity was depressed in the DEHP treated mice compared with the control mice. However other immunological parameters such as thymus and spleen mass, white blood cells were not affected by DEHP treatment.

Influences of DEHP on immune responses were carried out in rodents both in vitro and in vivo. For example, Koike et al. (2009) investigated the effects of DEHP on immune cells from atopic prone NC/Nga mice in vitro, and found that DEHP enhances bone marrow-derived dendritic cells differentiation and also enhances Th2 response in splenocytes [5]. However, DEHP treatment could inhibit B cell proliferation and reduces the abundance of IgM-secreting cells in cultured immune tissues [16]. Tonk et al. (2012) have found the immune system in juvenile and adult wistar rats had different sensitivity to DEHP exposure, in which more immune parameters were affected in juvenile rats compared to adult rats [6]. In our study, cellular immunity was depressed in Kunming mice after DEHP exposure. The disparate results with other researches might be due to the differences in species used, the treatment method and the immune parameters measured [5] [6] [15] [16].

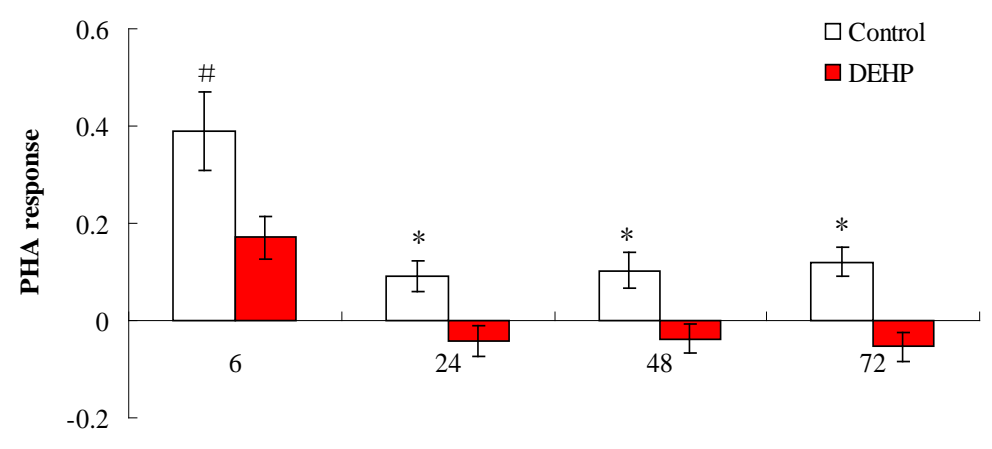

Time postimmunization (Hour)

Figure 2. Effect of DEHP treatment on PHA response in mice. Values are means \pm SE. PHA response was significantly higher in the control group than in the DEHP treated group. The white column represents the control group and solid column stands for the DEHP treated group. An asterisk $\left(^{*}\right)$ indicates statistical differences at $P<0.05$. A pound (\#) indicates nearly approaching the significant level.

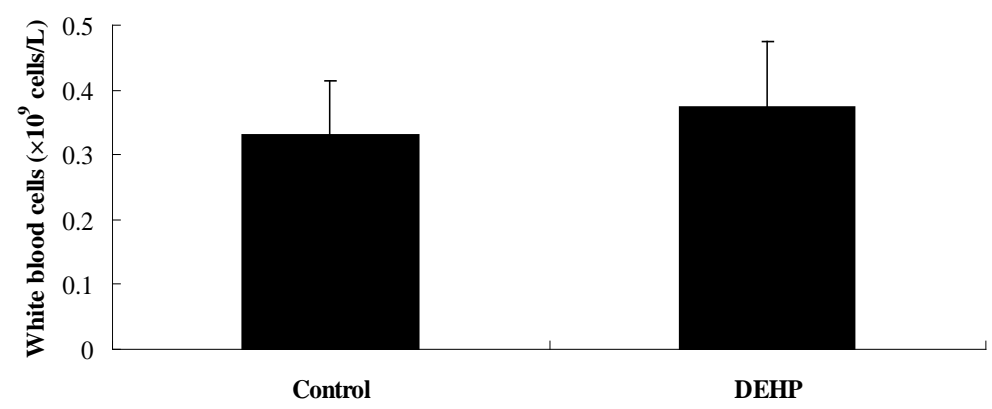

Figure 3. Effect of DEHP treatment on white blood cells in mice. Values are means \pm SE. WBC did not differ between the control and the DEHP treated groups. 
The major response to stress is the increase of stress hormones [24]. We found that adrenal gland increased nearly significantly after 42 days of DEHP treatment, which might imply the activation of the hypothalamic-pituitary-adrenal (HPA) axis. DEHP treatment might be a stressor to mice, although we did not detect the concentration of stress hormones such as corticosterone. Generally, corticosterone had suppressive effect on immune function. Therefore, the impairment of cellular immunity might be due to the increase of adrenal gland. Future work is required to examine the levels of stress hormones and their relationships with immune function.

In the present study, DEHP treatment decreased seminal vesical mass, which indicated its suppressive effect on reproductive function. This result was consistent with other researches [25] [26]. However, DEHP treatment had no effect on body mass and most organ masses in mice.

\section{Conclusion}

In conclusion, different immunological indices have different sensitivity to DEHP. DEHP had significant suppressive effect cellular immune response, whereas it did not affect thymus and spleen and white blood cells.

\section{Acknowledgements}

The present study was supported by grants from the National Natural Science Foundation of China (No. 31370427), Natural Science Foundation of Shandong province (ZR2013CM019), Crossing Research Project (hxkj2014001) and the Doctor Initiation Foundation (bsqd20100204) to DLX.

\section{References}

[1] Sheldon, B.C. and Verhulst, S. (1996) Ecological Immunology: Costly Parasite Defences and Trade-Offs in Evolutionary Ecology. Trends in Ecology and Evolution, 11, 317-321. http://dx.doi.org/10.1016/0169-5347(96)10039-2

[2] Owens, I.P.F. and Wilson, K. (1999) Immunocompetence: A Neglected Life History Trait or Conspicuous Red Herring? Trends in Ecology and Evolution, 14, 170-172. http://dx.doi.org/10.1016/S0169-5347(98)01580-8

[3] Nelson, R.J. and Demas, G.E. (1996) Seasonal Changes in Immune Function. Quarterly Review of Biology, 71, 511548. http://dx.doi.org/10.1086/419555

[4] Kaminogawa, S. and Nanno, M. (2004) Modulation of Immune Functions by Foods. eCAM, 1, 241-250. http://dx.doi.org/10.1093/ecam/neh042

[5] Koike, E., Inoue, K., Yanagisawa, R. and Takano, H. (2009) Di-(2-Ethylhexyl) Phthalate Affects Immune Cells from Atopic Prone Mice in Vitro. Toxicology, 259, 54-60. http://dx.doi.org/10.1016/j.tox.2009.02.002

[6] Tonk, E.C.M., Verhoef, A., Gremmer, E.R., Loveren, H. and Piersma, A.H. (2012) Relative Sensitivity of Developmental and Immune Parameters in Juvenile versus Adult Male Rats after Exposure to di(2-Ethylhexyl) Phthalate. Toxicology and Applied Pharmacology, 260, 48-57. http://dx.doi.org/10.1016/j.taap.2012.01.018

[7] Chou, K. and Wright, R.O. (2006) Phthalates in Food and Medical Devices. Journal of Medical Toxicology, 2, $126-135$. http://dx.doi.org/10.1007/BF03161027

[8] Barnes, D.K.A., Galgani, F., Thompson, R.C. and Barlaz, M. (2009) Accumulation and Fragmentation of Plastic Debris in Global Environments. Philosophical Transactions of the Royal Society of London, Series B, 364, 1985-1998. http://dx.doi.org/10.1098/rstb.2008.0205

[9] Meeker, J.D., Sathyanarayana, S. and Swan, S.H. (2009) Phthalates and Other Additives in Plastics: Human Exposure and Associated Health Outcomes. Philosophical Transactions of the Royal Society of London, Series B, 364, 20972113. http://dx.doi.org/10.1098/rstb.2008.0268

[10] Andrady, A.L. and Neal, M.A. (2009) Applications and Societal Benefits of Plastics. Philosophical Transactions of the Royal Society of London, Series B, 364, 1977-1984. http://dx.doi.org/10.1098/rstb.2008.0304

[11] Thompson, R.C., Swan, S.H., Moore, C.J. and Saal, F.S. (2009) Our Plastic Age. Philosophical Transactions of the Royal Society of London, Series B, 364, 1973-1976. http://dx.doi.org/10.1098/rstb.2009.0054

[12] Halden, R.U. (2010) Plastics and Health Risks. Annual Review of Public Health, 31, 179-194. http://dx.doi.org/10.1146/annurev.publhealth.012809.103714

[13] Duty, S.M., Singh, N.P., Silva, M.J., Barr, D.B. and Brock, J.W. (2003) The Relationship between Environmental Exposures to Phthalates and DNA Damage in Human Sperm Using the Neutral Comet Assay. Environmental Health Perspective, 111, 1164-1169. http://dx.doi.org/10.1289/ehp.5756

[14] Swan, S.H., Liu, F., Hines, M., Kruse, R.L., Wang, C., Redmon, J.B., Sparks, A. and Weiss, B. (2010) Prenatal Phthalate Exposure and Reduced Masculine Play in Boys. International Journal of Andrology, 33, 259-269. 
http://dx.doi.org/10.1111/j.1365-2605.2009.01019.x

[15] Kimber, I. and Dearman, R.J. (2010) An Assessment of the Ability of Phthalates to Influence Immune and Allergic Responses. Toxicology, 271, 73-82. http://dx.doi.org/10.1016/j.tox.2010.03.020

[16] Martins, K., Applegate, B., Hagedorn, B., Kennish, J. and Zwollo, P. (2015) Di(2-ethylhexyl) Phthalate Inhibits B Cell Proliferation and Reduces the Abundance of IgM-Secreting Cells in Cultured Immune Tissues of the Rainbow Trout. Fish \& Shellfish Immunology, 44, 332-341. http://dx.doi.org/10.1016/j.fsi.2015.02.037

[17] Smits, J.E., Bortolotti, G.R. and Tella, J.L. (1999) Simplifying the Phytohaemagglutinin Skin-Testing Technique in Studies of Avian Immunocompetence. Functional Ecology, 13, 567-572. http://dx.doi.org/10.1046/j.1365-2435.1999.00338.x

[18] Bellocq, J.G., Krasnov, B.R., Khokhlova, I.S. and Pinshow, B. (2006) Temporal Dynamics of a T-Cell Mediated Immune Response in Desert Rodents. Comparative and Biochemical Physiology Part A, 145, 554-559. http://dx.doi.org/10.1016/j.cbpa.2006.08.045

[19] Savino, W. and Dardenne, M. (2000) Neuroendocrine Control of Thymus Physiology. Endocrine Review, 21, $412-443$. http://dx.doi.org/10.1210/er.21.4.412

[20] Calder, P.C. and Kew, S. (2002) The Immune System: A Target for Functional Foods? British Journal of Nutrition, 88, S165-S176. http://dx.doi.org/10.1079/BJN2002682

[21] Smith, K.G. and Hunt, J.L. (2004) On the Use of Spleen Mass as a Measure of Avian Immune System Strength. Oecologia, 138, 28-31. http://dx.doi.org/10.1007/s00442-003-1409-y

[22] Xu, D.L. and Wang, D.H. (2010) Fasting Suppresses T Cell-Mediated Immunity in Female Mongolian Gerbils (Meriones unguiculatus). Comparative and Biochemical Physiology Part A, 155, 25-33. http://dx.doi.org/10.1016/j.cbpa.2009.09.003

[23] Yang, X.P. (2004) Laboratory Manual in Animal Physiology. Higher Education Press, Beijing, 91-94.

[24] Sapolsky, R.M., Romero, L.M. and Munck, A.U. (2000) How Do Glucocorticoids Influence Stress Responses? Integrating Permissive, Suppressive, Stimulatory, and Preparative Actions. Endocrine Review, 21, 55-89. http://dx.doi.org/10.1210/er.21.1.55

[25] Andrade, A.J., Grande, S.W., Talsness, C.E., Gericke, C., Grote, K., Golombiewski, A., Sterner-Kock, A. and Chahoud, I. (2006) A Dose Response Study Following in Utero and Lactational Exposure to Di-(2-ethylhexyl) Phthalate (DEHP): Reproductive Effects on Adult Male Offspring Rats. Toxicology, 228, 85-97. http://dx.doi.org/10.1016/j.tox.2006.08.020

[26] Christiansen, S., Boberg, J., Axelstad, M., Dalgaard, M., Vinggaard, A.M., Metzdorff, S.B. and Hass, U. (2010) LowDose Perinatal Exposure to Di(2-ethylhexyl) Phthalate Induces Anti-Androgenic Effects in Male Rats. Reproductive Toxicology, 30, 313-321. http://dx.doi.org/10.1016/j.reprotox.2010.04.005 